\title{
PHIlletegiteA
}

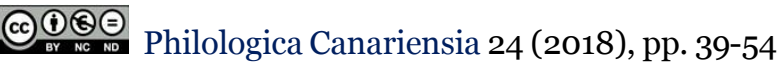

DOI: 10.20420/PhilCan.2018.196

Recibido: 10 de abril de 2018; aceptado: 21 de junio de 2018

Publicado: 18 de julio de 2018

\section{LITERATURA, HISTORIA Y SUBALTERNIDAD. EL LAZARILLO: ACCIONES Y PALABRAS DE UN SOMETIDO}

\author{
JOSÉ ANTONIO CALZÓN GARCÍA \\ Universidad de Cantabria
}

\begin{abstract}
RESUMEN: El artículo analiza la importancia del Lazarillo, y del género picaresco, a la hora de dar voz y presencia narrativa a un tipo de protagonista hasta entonces inaudito en la literatura y en la historia, repasando algunos posicionamientos que revindican la presencia del individuo anónimo en el discurso público. A partir de aquí se analiza cómo la revolucionaria estructura narrativa del Lazarillo aparece combinada en la obra con la estrategia de ofrecer el relato de un subalterno que juega a controlar tanto su discurso como sus acciones.
\end{abstract}

PALABRAS CLAVE: Lazarillo, enunciación, microhistoria, subalterno, poder, autobiografía

Literature, history and subalternity. Lazarillo: actions and words from a subservient

\begin{abstract}
This article analyzes the role of Lazarillo and the picaresque genre in giving voice and narrative presence to a kind of character unprecedented in literature and history. First, I will review some of the positions which claim the presence of the anonymous individual in public discourse, and then I will study how the revolutionary narrative structure of Lazarillo is combined with the strategy of offering the story of a subaltern who plays at controlling not only his discourse but also his actions.
\end{abstract}

KEYWORDS: Lazarillo, enunciation, microhistory, subaltern, power, autobiography

\section{INTRODUCCIÓN. MÍMESIS Y DIÉGESIS: LA HISTORIA FRENTE AL PODER}

Las relaciones entre la política y la representación más o menos mimética de la realidad circundante han discurrido por diversos caminos a lo largo de los siglos, si bien, como apunta Medina (2009, 128-129), "la historia por mucho tiempo fue el fragmento que reportaba los avatares del poder [...] esa historia que se vanagloria de las conquistas, que habla de vencidos y vencedores". Desde este prisma, los relatos históricos recurrían al tamiz de lo utópico para cribar una realidad que, de este modo, podía ofrecerse con efectos narcotizantes: "la utopía sería, entonces, el calmante, la anestesia que hace olvidar el dolor, no la conciencia que nos hace asumirlo como instancia realísima a la que el ser se ve sometido cotidianamente" (Medina, 2009, 137). Distorsión y mímesis, así, parecen jugar papeles antagónicos para todos aquellos que, de una u otra manera, juegan a la impostura de ofrecer a sus contemporáneos, 
o a quienes les sucedan, una narración pretendidamente veraz de sus tiempos o de los pasados. $Y$ en ese ámbito en el que se da forma textual al universo poliédrico y multiforme que nos envuelve, la cotidianidad, la rutina, revela, para algunos, el verdadero locus "donde realmente acontece la historia" (Medina, 2009, 130); al universo edulcorado del héroe de la épica medieval le sucederá, lentamente, "el drama del ser concreto, del hombre de carne y hueso; él lleva a la dimensión temporal y a las sociedades históricas la tragedia de su naturaleza concreta" (García Pérez, 1994, 37).

De este modo, la dialéctica entre la representación histórica y literaria del héroe -en el sentido clásico de la expresión- y el relato de lo cotidiano pudiera conllevar, tal y como las lecturas marxistas sugieren, un verdadero posicionamiento físico frente al conocimiento de la realidad (Asensi, 2009a, 60), bien desde la atalaya que proporciona el universo idealizado de la épica, bien desde la perspectiva en contrapicado del ser anónimo. No en vano, ambas posturas, por citar tan solo una muestra, han permitido segmentar en ocasiones la producción literaria española en compartimentos claramente deslindados, tal y como ejemplifican, en el siglo XVI, la narrativa idealista -bizantina, morisca, pastoril...-, por un lado, y el relato picaresco por otro. Tiempo habrá de volver sobre estas cuestiones más adelante.

\section{HISTORIA Y DONNADIES, O EL RELATO DEL INDIVIDUO SIN ROSTRO}

Sobradamente conocido es el concepto unamuniano de intrahistoria, una idea que, simplificando mucho, desposee a la historia de su capacidad para la agencia o, si se prefiere, dota a la colectividad de protagonismo, pero no de intencionalidad: “'intrahistoria' es primeramente y ante todo, lo 'intraconciente' o inconsciente, aplicado a la historia, a la vida colectiva, según las palabras del propio Unamuno, para quien lo 'intra-histórico' no es sino lo inconsciente en la historia" (Fernández Turienzo, 1997, 94). Esa idea de la vida colectiva, basada en los postulados de Wilhelm Wundt acerca de la völkerpsychologie, o psicología de los pueblos (Gutiérrez, 1989, 266), permite indagar no solo en el pasado reciente, sino en el mismo presente, a partir del "estudio de la cotidianidad y de lo local" (Medina, 2009, 123). Frente al ámbito de lo épico, Unamuno opondrá como objeto de estudio al antihéroe: "para Unamuno, la historia debería interesarse en los caminos que protagonizan sus actores periféricos; es decir, en la senda que recorrieran aquellos hombres que hacen la historia de manera inconsciente [...] los hombres que no aspiran al título de héroes" (Medina, 2009, 123).

De este modo, el ámbito monumental de lo mítico - reforzado por la producción histórico-literaria - dejaría paso al relato silencioso del individuo anónimo, en una nebulosa narrativa donde las jerarquías humanas carecerían de sentido: "Unamuno propone una intrahistoria sin héroes, en la que las jerarquías de los protagonismos desaparecen. El hacer intrahistórico es una tarea de todos. Todos los hombres importan en tanto que contribuyen a impulsar el continuum de la tradición eterna" (Medina, 2009, 127). En el universo intrahistórico es lo profundo, lo que no salta a la vista, lo que dota de sentido a la verdadera historia (Margenot, 2009). Frente a la historia en cuanto materia muerta, la intrahistoria representa la tradición como sustancia que vivifica el presente, es la parte de la historia que no aparece en los periódicos; de la intrahistoria surge el presente, es algo vivo, pero a la vez, paradójicamente, puede ser entendida en cuanto retrato de la inmovilidad, esto es, como una 
auténtica defensa de la situación - buena o mala- en que se halla el pueblo (Ribas Ribas, 1971, 28-29, 33).

No fue don Miguel, como sabemos, el único que insistió en el papel protagónico de "la vida cotidiana, llevada por seres anónimos" (Bender, 2016, 77-78). En efecto, el relato de las "vidas humildes y anónimas que forman la esencia de lo social" (Arias, 2000, 1), de "la pequeña historia, la historia del hombre de a pie" (García Pérez, 1994, 48), tendrá en autores como Carlo Ginzburg una sólida continuación, a través de la microhistoria y del camino abierto por el historicismo postmoderno, poniendo "en la misma escena la cotidianidad, el localismo y la vida de los seres periféricos cuyas voces fueron silenciadas por la historia clásica" (Medina, 2009, 131). Ese individuo anónimo, alerta Sharpe (1996), en modo alguno ha de verse cosificado, reducido al mero rol de obrero, de damnificado, de inmigrante, viendo así anulada su vida cotidiana en pro de lo genérico (Medina, 2009, 132). Por el contrario, esa historia desde abajo habrá de consistir en "explorar las experiencias históricas de las personas cuya existencia tan a menudo se ignora, se da por supuesta o se menciona de pasada en la corriente principal de la historia" (Sharpe, 1996, 40). Para Sharpe, este enfoque cumple dos funciones: 1) sirve de "correctivo a la historia de las personas relevantes" (1996, 50), y 2) "abre al entendimiento histórico la posibilidad de una síntesis más rica, de una fusión de la historia de la experiencia cotidiana del pueblo con los temas de los tipos de historia más tradicionales" $(1996,51)$. De igual modo, la historia desde abajo "ofrece también el medio de restituir a ciertos grupos sociales una historia que podría haberse dado por perdida o de cuya existencia no eran conscientes" (Sharpe, 1996, 55-56): "la mayoría de quienes han escrito historia desde abajo aceptarían, en términos generales, la idea de que uno de los resultados de haber abordado las cuestiones de ese modo ha sido demostrar que los miembros de las clases inferiores fueron agentes cuyas acciones afectaron al mundo (a veces limitado) en que vivieron" (Sharpe, 1996, 56).

Otra idea que añadir a la intrahistoria, a la microhistoria o a la historia desde abajo es la de subalternidad. Planteada en el ámbito hispano, entre otros, por Manuel Asensi, la subalternidad muestra al elemento nuclear de su estudio, los subalternos, como "aquellos grupos cuyo común denominador es la imposibilidad de satisfacer unas necesidades vitales sin las que resulta en extremo difícil vivir la propia vida" (Asensi, 2009b, 35). Desde esta perspectiva, el individuo sin voz ni rostro, más que actuar, sufre las acciones de otros (Asensi, 2009a, 52), alejado de cualquier élite social, sin identidad -"el Otro no es, sirve", que dirá Martínez (2004) - y sometido políticamente (Asensi, 2009b, 23): "el subalterno ve administrados su cuerpo y su mente de una manera en que es conducido a una agonía que supone para él o para ella un callejón sin salida” (Asensi, 2009b, 36). No obstante, la subordinación política del subalterno puede llevarle a una paradójica, o contradictoria, relación con el poder, llegando en ocasiones a pactar con la clase dirigente, a fin de preservar su posible nuevo estatus: "el subalterno se desprende de su función de subalternidad en el momento en que toma conciencia de que ya puede sobrevivir, y ello da cuenta de todos esos casos en los que un subalterno [...] puede entrar a formar parte del aparato hegemónico" (Asensi, 2009b, 37-38). De cualquiera de las maneras, el estatus del subalterno se ve configurado a partir de una relación de alteridad donde todo gravita en torno al eje del poder: "el lugar de lo subalterno es un espacio co-construido en forma dinámica entre quien ocupa la posición dominante y quien la padece" (Abad García, 2011, 41).

En resumen, desde la intrahistoria unamuniana hasta la subalternidad postcolonialista, pasando por la microhistoria italiana, diversas corrientes de análisis del discurso histórico- 
literario han venido consolidando, ya desde el siglo XX, la idea de que el sujeto al que se le ha otorgado el privilegio de la representación textual, durante siglos, no solo ofrece una versión deformada - y escasamente representativa, si se nos apura- del hombre de su tiempo, sino que ha contribuido a consolidar un statu quo en el cual poder y representación crean un bucle que se retroalimenta, dejando así excluido del discurso público y escrito al ciudadano 'medio' - si es dable atribuir esta cualidad a alguien- y al individuo marginal.

\section{ENUNCIACIÓN Y VISIBILIDAD: EL SILENCIO COMO AUSENCIA}

Uno de los aspectos más destacados por parte de los estudiosos de la subalternidad es la relación entre esta y la enunciación. Así, como Asensi ha señalado con frecuencia, el subalterno es definido en gran medida por su ausencia de voz, si bien no poder hablar puede querer decir "no que estés mudo, sino que lo que dices no es escuchado o no es comprendido de forma adecuada" (2009b, 29-30). Como consecuencia de ello, "el acto de habla realizado por el subalterno no es sancionado (institucionalmente) por el receptor" (2009b, 30), lo que lleva a aquel, sencillamente, a enfrentarse a la castrante conclusión de que no puede hablar por sí mismo, o que como mínimo su voz precisa de la adecuada mediación para ser recibida en el discurso público. No obstante, la condición de subalternidad, y he aquí un endiablado callejón sin salida, "existe y cobra sentido como lugar y condición en tanto tiene como objeto de referencia a quien lo interpela como tal" (Abad García, 2011, 40). Es decir, el subalterno carece de representación, de enunciación en el discurso público, excepto en cuanto figura pasiva a la que remitir en cuanto referente, nunca en cuanto agente. Del subalterno se habla, pero no habla.

Desde el punto de vista puramente textual, el discurso del subalterno ha de sufrir la marginación o, sencillamente, el silencio, fruto de la apropiación de las narrativas, de las estéticas, por parte de "los dominadores" (Abad García, 2011, 49): "el subalterno como sujeto evidentemente puede hablar físicamente [...] el problema reside en que sus palabras no tienen una validez dialógica, lo cual se deriva de que la posición que ocupa no es reconocida e interpelada como válida en una situación de habla” (Abad García, 2011, 53). Como consecuencia de ello, cualquier intento por parte del 'intelectual' de representar al subalterno no es más que una operación que tiene como consecuencia la configuración del subalterno en cuanto sujeto incapaz "de pronunciarse en su propio nombre" (Abad García, 2011, 53), y aun en el caso de que este se hiciera oír, de una u otra forma, en sus palabras figuraría el eco del discurso dominante y de la escena hegemónica, en consonancia con la idea bajtiniana de que la voz del interlocutor siempre está presente en el decir del sujeto enunciante, de ahí el efecto polifónico de todo discurso (Rufer, 2013, 94).

La idea del posicionamiento del subalterno en relación con la narrativa dominante nos lleva a la noción de discurso social, esto es, "las reglas de encadenamiento de enunciados que, en una sociedad dada, organizan lo decible - lo narrable y lo opinable- y aseguran la división del trabajo discursivo" (Angenot, 2010, 21). En efecto, hablar de discurso social supone abordar el ámbito de lo decible en estrecha conexión con el ámbito de lo hegemónico: "la hegemonía discursiva sólo es un elemento de una hegemonía cultural más abarcadora, que establece la legitimidad de los diversos estilos de vida, de las costumbres, actitudes y mentalidades que parece manifestar" (Angenot, 2010, 31). Por tanto, la hegemonía daría lugar a un discurso donde, fruto de la relación asimétrica entre las distintas clases sociales, el 
grupo dominante crearía su propia narrativa autolegitimadora (idioma, gnoseología, tabúes, visión del mundo, topología...), imponiendo estrategias cognitivas al subalterno (Angenot, 2010, 73).

En vista de lo apuntado, parece a todas luces incuestionable la estrecha imbricación existente entre enunciación y poder. Los grupos dominantes crean, de una u otra manera, "sistemas modelizantes" cuyo objetivo sería "la incitación y apelación a los individuos para que estos realicen acciones y produzcan discursos, hasta el punto de que se puede decir que un sistema modelizante se define por su carácter incitativo, apelativo y performativo" (Asensi, 2007, 137). La performatividad del acto enunciativo, en el caso de los sistemas modelizantes, pasaría, por tanto, por un ejercicio logocéntrico - no exactamente en el sentido derridiano- en función del cual el grupo hegemónico reforzaría su propio discurso en la medida en que este fuese usado una y otra vez.

Como comenzaremos a desarrollar a partir del siguiente apartado, la contraposición entre los grupos dominantes - poseedores, en última instancia, del discurso social- y los subalternos - silenciados o subordinados en actos comunicativos que les tendrían como meros sujetos pasivos- guarda cierta relación analógica con la idea orteguiana de la contraposición entre épica y novela (Gutiérrez, 1989, 270). Así, la novela, con el discurrir de los siglos, comenzará a revelarse como el género que resquebraja, al menos en ocasiones, un sistema modelizante donde la voz del subalterno -llamémosle antihéroe, outsider o simplemente individuo anónimo- no era hasta entonces oída, logrando así que la voz silenciada del excluido se abra cierto hueco dentro del discurso público, si bien en la mayoría de los casos de manos de un representante del grupo dominante: el intelectual.

\section{LITERATURA, AUTOBIOGRAFISMO Y PODER}

Manuel Asensi (2007) ha insistido repetidamente en reivindicar el valor de la crítica literaria en cuanto mecanismo de resistencia a la autoridad, siempre y cuando se haga cargo de las formas literarias que conforman nuestra manera de percibir el mundo. Así, la literatura, como los demás medios de expresión, son elementos "a través de los cuales se cumple la acción modeladora de los aparatos ideológicos heterogéneos y plurales del Estado, de los grupos de presión o del Imperio" (Asensi, 2007, 135-136). Esa acción modeladora consistiría en crear individuos que "se representan, perciben y conciben el mundo y a sí mismos según modelos previamente codificados, esto es, ideológicos, cuya finalidad es la práctica de una política normativa y obligatoria, y cuya estrategia consiste en representarse como naturales" (Asensi, 2007, 136). Desde este prisma, la crítica - entendida como sabotaje, al modo de Asensi- analizaría la ideología dominante, presente en los textos literarios, y la subordinación a esta de los subalternos, teniendo en cuenta "la relación entre las condiciones materiales de los subalternos y la semiótica representativa que los forma y engloba" (Asensi, 2009b, 38).

Si nos enfrentamos, desde el patrón semiótico, a los moldes literarios que han podido, de alguna manera, replantear las relaciones entre el poder y el individuo sin rostro, el autobiografismo surge como una forma de narrar que suscita nuevas reflexiones acerca de las relaciones sígnico-políticas asimétricas. Así, Coll-Tellechea $(2015,153)$ apunta cómo en el germen de la narración personal, del relato (auto)biográfico, podría estar el desarrollo de la monarquía absoluta, a lo largo de los siglos XV y XVI, y el surgimiento de toda una camarilla 
de nobles advenedizos preocupados por dotar - a través del discurso oral o escrito- a su persona, y linaje, con la aureola necesaria para codearse, sin problemas de sangre, con la realeza en los círculos palaciegos, siendo así que determinados moldes literarios, como el picaresco, podrían responder burlonamente al esquema, vigente entonces, de dar "respuesta a las demandas administrativas (burocráticas) del Estado en relación a las relaciones de méritos y servicios" (Coll-Tellechea, 2015, 154). De igual modo, Molho (1983, 133) ha ahondado también en las implicaciones de la irrupción de la primera persona en la literatura, desde el prisma de las relaciones de poder:

La persona yo -la del hablante hablando de sí- es persona de diferencia, que marca su especificidad diferencial contrastando con la persona tercera, que es la de la no-diferencia. De la diferencia nace la singularidad intrínseca del ser, y de la no-diferencia su proyección múltiple en representaciones idénticas, indefinidamente repetibles. Todas las personas terceras son, como terceras, intrínsecamente iguales, y sólo difieren entre sí por el yo que cada una de ellas interioriza; y recíprocamente toda primera persona, pese a su irreductible singularidad, es potencialmente tercera persona multiplicable por delocución.

Desde la perspectiva del subalterno y su relación con el poder, otros estudiosos (Bender, 2016, 68) han apuntado también el posible valor terapéutico que el relato autobiográfico pudiera comportar, primero comprobado en las ciencias psicológicas y, más recientemente, dentro de la crítica literaria, como podría ejemplificar, a modo de muestra, la figura del escritor -y partícipe en dos guerras- Arturo Barea, de acuerdo con las tesis de la propia Bender (2016). De cualquiera de las maneras, y volviendo al siglo XVI, el uso de la narración en primera persona había de recurrir con frecuencia a la excusa de la ejemplaridad (CollTellechea, 2015, 159), al objeto de que el propio escritor se curase en salud ante el peligro evidente de ser sancionado por servirse de una fórmula exclusiva hasta entonces del relato más o menos épico, protagonizado por virtuosos religiosos o aguerridos soldados, todos ellos quintaesencia de la virtud. Y, de este modo, el Renacimiento asistirá al desarrollo de dos líneas novelescas claramente diferenciadas, no solo por sus características formales y temáticas, sino por su posicionamiento respecto al poder establecido: a) una, según Rey Hazas (1982, 81), que prolonga el camino de los "libros de caballerías y las novelas sentimentales, por medio de narraciones pastoriles, moriscas y bizantinas" ("carácter idealista, convencional y [...] ficticio de la trama", centrada en el amor y con personajes con características heroicas y nobles), con predominio de la tercera persona en la narración y final feliz; y b) otra "sin idealizaciones, ni fantasías" en la que predomina la primera persona, donde no existe una visión idealizada del amor, con una serie de personajes -alejados por lo general de la nobleza- que buscan "la satisfacción de las necesidades primarias" (Rey Hazas, 1982, 82) y que evolucionan en ocasiones psicológicamente, al tiempo que ofrecen una visión crítica del mundo (Rey Hazas, 1982, 81-83). Acababa de nacer el relato del subalterno.

\section{PICARESCA, HEGEMONÍA Y SUBALTERNIDAD: LA LUCHA POR EL PODER Y LA DENUNCIA DEL EXCLUIDO A TRAVÉS DE LA ENUNCIACIÓN}

Como señala Coll-Tellechea $(2015,148)$, "el desarrollo de la picaresca estuvo marcado por la relación de dependencia del campo literario con respecto al campo de poder"; es decir, picaresca y política, de alguna manera, parecen haber tenido una estrecha interconexión 
durante el Siglo de Oro, potenciada, según la misma autora, por la intervención inquisitorial a propósito de la publicación del Lazarillo $(2015,157)$. La figura del pícaro parece encajar con absoluta idoneidad con el perfil del subalterno sojuzgado por las clases dominantes. Así, Cela $(1985,37)$ definía al personaje más específico de nuestra literatura en los siguientes términos:

Tipo humano descarado, apaleado y resignado que vivió en la España de los siglos XVI y XVII rodeado de un ambiente convenidamente hostil y zarandeado por gobernantes tenidos por ecuánimes en su obediente ceguera, clérigos vapuleadores en su falta de caridad y caballeros soberbios en su fanfarria que pronto habría de trocarse en derrota; a su hambre, los historiadores le suelen llamar inadaptación, cuando no le aplican peores y más crueles epítetos.

En efecto, el pícaro emerge en la literatura española como un individuo sometido a las miserias morales de los grupos dominantes, pero también como una consecuencia social de un nuevo modelo económico-político, surgido en el XVI, cuando el hombre europeo pierde la protección del señor feudal, sobreviviendo en un mundo donde predominan las relaciones de dinero y vendiendo lo único que tiene, esto es, su fuerza de trabajo. No obstante, previamente a ser empleado por la industria, el individuo anónimo del XVI asiste a su propia 'liberación', por lo cual muchos no encuentran uso para su fuerza de trabajo y habrán de sobrevivir recurriendo a su ingenio (Blanco Aguinaga, 1983, 50-51). De este modo, el pícaro es una consecuencia moral y social de la ventana a la libertad que abrirá la disolución del modelo medieval.

En este contexto en el que se desarrolla la novela picaresca, el Lazarillo se presenta como uno de los modelos más evidentes a la hora de buscar un análisis comparativo, en clave política, con el debate contemporáneo en torno a la subalternidad: "el Lazarillo de Tormes es un documento esencial en el debate sobre la subalternidad tal y como se ha venido desarrollando desde mediados de los años 80" (Asensi, 2009a, 50). Para el subalterno, y específicamente para el pícaro, el código moral viene determinado en términos estrictamente materiales: "buenos son aquellos que comen y dan de comer" (Asensi, 2009a, 57). De este modo, la condición de subalterno, de excluido, de Lázaro, se verá confirmada una y otra vez a lo largo del relato, en base sobre todo a cuatro pilares (Asensi, 2009a, 62-63): la clase (su condición de 'pobre'), la ley (su padre era ladrón y él mismo ejercerá la mendicidad, actividad prohibida en ciertos períodos del siglo XVI), la raza (no olvidemos la condición de 'negro' de su padrastro) y el sexo (a través del posible ejercicio de la prostitución por parte de su madre y de su pasividad en cuanto víctima de una sodomía real o simbólica). Desde otro punto de vista, también Martínez (2004) considera a Lázaro un excluido, tanto en el plano social como en el literario. Así, "Lázaro resulta descalificado en los tres ejes de relación con el Otro" que Todorov $(1987,195)$ señala: 1) el axiológico (no tiene "honor ni valor"); 2) el praxeológico (es "un inferior, apto sólo para cumplir órdenes; su destino es servir"), y 3) el epistémico ("no es objeto de conocimiento, sino a lo sumo de divertida o condescendiente curiosidad").

En resumen, el pícaro surgió como personaje literario en una España -y Europa- en transición. Arrojado a las calles sin amo ni señor, el pícaro se ve subordinado a un nuevo orden social en el cual la prioridad es sobrevivir. La novela picaresca, con una gama amplísima de protagonistas y contextos, da buena cuenta del primer subalterno de los tiempos modernos en los cuales, sin embargo, el individuo anónimo podrá ver recuperada su voz a través de la narrativa. 


\section{ANÁLISIS DEL LAZARILLO. LA SUBVERSIÓN A TRAVÉS DE PALABRAS Y ACCIONES}

\section{a) Acción y poder: Lázaro subordinado}

El personaje de Lázaro, a lo largo de la obra, se enfrenta a una serie de acciones controladas por aquellos que están por encima de él, asumiendo el rol de sujeto pasivo y reactivo (Asensi, 2009a, 53) al que solo le queda intentar sobrevivir, a partir de "uno de los tópicos que instala la literatura picaresca: el dinero lo compra todo [...] y condiciona las relaciones sociales" (Cabado, 2011, 134). En la obra, el poder será ejercido de forma ambivalente, en el sentido de que "nadie lo posee en propiedad, aunque sin embargo casi todos son capaces de ejercerlo" (Asensi, 2009b, 34). En efecto, el poder será uno de los temas cruciales de la obra, y con él la subordinación del protagonista desde dos órdenes fundamentalmente: el físico y el enunciativo. Comencemos con el primero de estos.

Lázaro arranca su relato desde la impostura obligada por las reglas de la retórica: su historia, en una desafiante primera persona, no va a ser narrada desde el encumbramiento que otorga la virtud moral, al "no ser más sancto que mis vecinos" (Anónimo, 2006, 8). ${ }^{1}$ De este modo, el protagonista realiza el primer acto de subordinación, fingido o no, al caracterizarse como un pecador, lo cual vuelve la narración, a pesar del tópico, descaradamente novedosa, optando por un narrador autodiegético carente de cualidades morales que justifiquen su relato.

Desde el momento en el que arranca la historia en sentido estricto, Lázaro adquirirá la condición de subalterno cuando su madre convierta al ciego en su primer amo, delegando en él la capacidad para el control sobre el protagonista: "me encomendó a él” (p. 21), "yo le comencé a servir" (p. 22). Una vez asumido el nuevo rol por el muchacho-narrador - "me fui para mi amo" (p. 22)-, a Lázaro solo le quedará aceptar con desolación la brutal relación dialéctica que le opone al universo circundante, en especial tras el momento catártico que marca la calabazada contra el toro de piedra: "me cumple avivar el ojo y avisar, pues solo soy, y pensar cómo me sepa valer" (p. 23).

Serán tiempos duros para el chico, agravados por el peligro de la violencia física aconsejada por las gentes a su amo como mecanismo para la corrección: "castigaldo, castigaldo, que de Dios lo habréis" (p. 34). En efecto, el ciego recurrirá a su superioridad física en más de una ocasión, y el Lázaro narrador recuerda de forma vívida los excesos de su amo: "si al ruido no acudieran, pienso no me dejara con la vida [...] yo estaba tan maltratado" (p. 41). Dichos abusos serán objeto de chanza y relato por parte de un ciego al que el uso de la violencia no le amedrenta: "contaba cuántas veces me había descalabrado y arpado la cara" (p. 43).

Poco mejorarán las cosas con el clérigo. A la violencia física la sucederá, incrementada, el hambre, sufrimiento definitorio, con frecuencia, del subalterno: "yo me finaba de hambre" (p. 47). No obstante, y si bien la falta de alimento, y las estrategias para solucionarlo, marcarán su estancia en casa del clérigo, no es menos cierto que el episodio crucial -el descubrimiento del duplicado de la llave con la que el pícaro lograba abrir el arca de su amo- que marca el fin de la convivencia de Lázaro con el segundo de sus amos pasa por un ejercicio de violencia - fruto del temor, eso así, a la presencia de una culebra en la cama del chico- que explicita una vez más la relación de subordinación: "con toda su fuerza me descargó en la cabeza un tan gran golpe, que sin ningún sentido y muy mal descalabrado me dejó” (p. 68). 
Abandonado el clérigo, la relación de obediencia y subordinación volverá a explicitarse cuando el escudero pregunte a un desocupado Lázaro por sus planes inmediatos: "Mochacho, ¿buscas amo?” (p. 72). Cierto es que a partir de ahora la violencia física dejará de definir la relación entre el pícaro y su amo, pero la presencia del hambre -en el caso del escudero marcada por el juego de apariencias que este sostiene- se irá intensificando, llevando así a la desesperanza al protagonista, víctima de la desventura: "Cuando esto le oí [...] estuve en poco de caer de mi estado [...] allí se me presentaron de nuevo mis fatigas [...] lloré mi trabajosa vida pasada y mi cercana muerte venidera [...] iMaldita tanta medicina y bondad como aquestos mis amos que yo hallo hallan en la hambre!" (pp. 76-77).

De este modo, la congoja de Lázaro le lleva a una situación de desesperanza total - "pedí a Dios muchas veces la muerte" (p. 81) -, a medida que constata que las expectativas de ver al escudero en cuanto proveedor de comida en la casa que comparten son del todo injustificadas: "si [...] por ventura trajese algo que comiésemos; más en vano fue mi experiencia” (p. 87). Y así, el muchacho configurará una visión de la vida en la cual toda alegría o satisfacción será siempre parcial, deslucida por la estoica aceptación de que, antes o después, los males volverán: "está constituido en mi triste fortuna que ningún gozo me venga sin zozobra” (pp. 95-96). No en vano, Lázaro será víctima no solo del hambre, sino, indirectamente, de las deudas de su amo, lo que refuerza su situación de subordinación social: "prended a este mozo, que él sabe dónde está (el escudero)" (p. 107).

Abandonado por el escudero, Lázaro irá pasando, más brevemente, a juzgar por el relato, de amo en amo, si bien sus infortunios no parecerán verse menguados por ello: "estuve con este mi quinto amo cerca de cuatro meses, en los cuales pasé también hartas fatigas" (p. 125); "después desto, asenté con un maestro de pintar panderos [...] y también sufrí mil males" (p. 125). Posteriormente, y tras su experiencia con el alguacil (p. 127), Lázaro, renunciando a seguir sirviendo a distintos amos, convertirá al arcipreste en una nueva figura rectora, quien, como sabemos, 'limpiará' su imagen a través del matrimonio de su criada con Lázaro —“teniendo noticia de mi persona el señor arcipreste [...] mi señor [...] porque le pregonaba sus vinos, procuró casarme con una criada suya” (p. 130)-, situación esta que convertirá al religioso, en una suerte de quid pro quo, en protector del protagonista, a costa de su honra: "tengo en mi señor arcipreste todo favor y ayuda" (p. 131).

A pesar de que el relato de Lázaro no hace más que poner de manifiesto la situación de constante subordinación física y moral a la que su vida y origen le abocan, lo cierto es que en su peregrinaje por la vida solo un rol parece dotarle de cierto poder, desde el punto de vista social: su condición, al final de la obra, de pregonero. En efecto, como el mismo narrador indica, la suerte parece al fin sonreírle: "Todos mis trabajos y fatigas hasta entonces pasados fueron pagados con alcanzar lo que procuré, que fue un oficio real, viendo que no hay nadie que medre, sino los que le tiene [...] tengo cargo de [...] acompañar los que padecen persecuciones por justicia y declarar a voces sus delitos” (pp. 128-129).

Lázaro, al margen de que sus declaraciones sean o no una impostura, parecerá verse así "en la cumbre de toda buena fortuna" (p. 135) al final de la obra, tras un proceso que habría comenzado, como explica en el tratado sexto, cuando el capellán le ponga a vender agua por la ciudad: "éste fue el primer escalafón que yo subí para venir a alcanzar la buena vida" (p. 126). En su condición de aguador, Lázaro sentirá también que su estatus social ha subido hasta el punto de considerar indigno para sí mismo el trabajo que le ha hecho tener dinero por primera vez en su vida: "desque me vi en hábito de hombre de bien, dije a mi amo se tomase su asno, que no quería más seguir aquel oficio” (p. 127). 
Esta aparente disolución de la subalternidad física no será más que el punto final de un proceso desarrollado a lo largo de la vida-relato, y al que asistimos ya con el ciego, cuando Lázaro entiende que ha de tomar la iniciativa si no quiere morir de inanición: "si con sotileza y buenas mañas no me supiera remediar, muchas veces me finara de hambre" (p. 27). Al margen de las artimañas para conseguir vino o comida, célebres en el primer tratado, el pícaro recurrirá al único elemento que le otorga una posición privilegiada respecto al viejo, la vista, para servirse de la venganza como mecanismo de compensación emocional ante los desmanes del ciego: "yo siempre le llevaba por los peores caminos" (p. 34). De igual modo, durante el tiempo que permanece al lado del escudero, Lázaro subvertirá la habitual situación de dependencia y sometimiento en lo que al sustento respecta, en la medida en que ahora será el muchacho quien logre comida para amo y criado: "viniese a topar con quien no sólo no me mantuviese, más a quien yo había de mantener [...] hoy día, cuando topo con alguno de su hábito [...] le he lástima con pensar si padece lo que aquél le vi sufrir” (pp. 91-92). La subversión se verá perfectamente escenificada en la parte final del tratado, cuando el propio Lázaro confiese que "me dejó mi pobre tercero amo" (p. 110), a diferencia de lo que solía ser habitual, esto es, que el amo decidiera sobre el futuro del muchacho, y no sobre el propio.

En resumen, las acciones del Lázaro personaje evidencian de principio a fin una situación de sometimiento por parte de diversos amos que se sirven con frecuencia del hambre como mecanismo de control. Con el escudero la situación se invertirá y en los tratados finales podemos asistir al esfuerzo por parte del protagonista por ascender en la escala social, escapando así de su sempiterna condición de subordinado, a pesar de que, paradójicamente, su relación con el arcipreste, en el tratado séptimo, le lleva a esa supuesta "cumbre de toda buena fortuna", a costa de aceptar la humillación social que conllevaba casarse con la amante del religioso.

\section{b) Lázaro habla: la enunciación como recurso}

El uso de la enunciación como mecanismo de poder, en el caso particular del Lazarillo, se hace ya a todas luces evidente desde ese prólogo revolucionario donde se anuncia en primera persona el relato de una vida que, como se verá, carece de toda ejemplaridad. Por ello, las artes retóricas habrán de envolver esas primeras páginas, para no hacer el texto aún más irreverente de lo que resultará. En este sentido, como el propio Cabado $(2011,133)$ reconoce, tradición y sorpresa se combinarán en el prólogo:

El peligro que implicaba tratar ciertos temas y hacerlos públicos es evidenciado en el prólogo, identificando la escritura con la labor del soldado que lucha al descubierto por honrarse [...] El fragmento, además, sugiere una postura estética que no se relacione con lo esperado por el público, con ese círculo vicioso que se genera a partir de los autores que escriben lo que se les pide.

Como sabemos, el Lazarillo no deja de ser un juego donde alguien letrado asume la voz ${ }^{2}$ de un niño presumiblemente analfabeto. Esta ironía, en cierto modo, descansa en la idea apuntada por Asensi (2009b, 22), cuando afirma que "si el subalterno no puede hablar, y el intelectual no lo representa, entonces estamos abocados al silencio más absoluto”. Ese Otro, que en el discurso público es construido con frecuencia como una figura a descalificar, adopta 
en el Lazarillo el doble rol de protagonista y narrador e, incluso, de pretendido autor real de la obra, en base a su anonimia, dejando así el género del texto a caballo entre la novela que se niega a sí misma y el falso documento testimonial (Martínez, 2004). Y así, Lázaro usará su supuesto propio discurso para subvertir no solo el patrón del molde novelesco sino la propia moral del statu quo:

La novela picaresca carece de motivación social aunque no de cierta intención política, no por tan solo presentida menos real y evidente. El pícaro atenta por instinto contra la norma de moral política del poderoso de su tiempo, cuya más alta [...] meta en esta vida efímera es la salvación de su alma de cara a la otra vida inmortal y bienaventurada (Cela, 1985, 40).

Si echamos un vistazo al propio relato, podemos ver ya desde las primeras páginas ese interés en que "vengan a noticia de muchos" (p. 3) las penas y padecimientos de un personaje que desafía la lógica narrativa de la época convirtiéndose en narrador autodiegético, para que "a todos se comunicase" (p. 5) el relato de una vida sin honor, siendo la mayor recompensa para el relator de tales 'hazañas' el propio conocimiento público de estas, pues todos los escritores "quieren [...] ser recompensados [...] con que vean y lean sus obras" (p. 6). De este modo, Lázaro parece recurrir desde el primer momento a la enunciación no solo en cuanto mecanismo de representación, sino también, de forma desafiante, como signo de ostentación verbal, dando así voz al individuo anónimo silenciado hasta entonces, salvo excepciones, por la literatura. El autor-narrador, en efecto, se vanagloria de ofrecer ante nuestros ojos el relato de una vida que ejemplifica la de tantos otros que "con fuerza y maña remando salieron a buen puerto" (p. 11), comentario este que desliza la postura del autor-narrador entre el cinismo y la insolencia, una vez terminada la lectura de una vida tan deshonrosa al final como al principio.

La enunciación, en el texto, funcionará también como un mecanismo compensatorio por parte del propio personaje, quien en ocasiones, gracias a ella, logrará soportar los infortunios de su vida. Así, en el caso del clérigo de Maqueda, Lázaro deseará la muerte por los beneficios nutricionales que el velatorio del finado le reportaría: "con todo mi corazón y buena voluntad rogaba al Señor [...] más que le llevase de aquesto mundo” (p. 53). Otras veces, la enunciación ayudará a su sustento de forma mucho más directa, tal y como sucederá con el escudero: "comienzo a pedir pan por las puertas" (p. 87). El personaje, llegado el caso, estará incluso dispuesto a utilizar la forma más deshonrosa de enunciación, la delación, para lograr sobrevivir, siendo de nuevo el episodio del escudero el que mejor lo retrata, cuando, atemorizado por las autoridades y los acreedores de su amo, una vez desaparecido este, Lázaro confiese que "hube mucho miedo y, llorando, prometíle de decir lo que preguntaban" (p. 108).

La enunciación, en manos del narrador, servirá también para contrabalancear la subordinación física del Lázaro actante, en la medida en que el control sobre el relato permitirá jugar con la baza de la elipsis, tal y como sucede con el incómodo episodio del fraile de la Merced: "y por esto y por otras cosillas que no digo salí dél” (p. 111). Por tanto, podríamos concluir que, en el Lazarillo, la enunciación juega un doble papel, desde el rol del personaje y desde el del narrador. Así, mientras que para el segundo es el mecanismo con el que dar voz al individuo silenciado, al primero le sirve, con frecuencia, para contrarrestar los efectos de los agentes opresores a los que se ve subordinado a lo largo de su vida. 


\section{c) Subordinación y enunciación}

Volviendo al problema enunciativo que plantea el Lazarillo - esto es, el uso de la primera persona por parte de un don nadie-, no podemos olvidar que la estructura narrativa fundamental de la obra, al margen del recurso del infame narrador autodiegético, se sustenta sobre un acto de subordinación, como ha apuntado Asensi (2009a, 53): "la iniciativa del acto de enunciación en virtud del que Lázaro se dirige a 'Vuestra Merced' no ha dependido de él [...] Un sujeto que escribe porque le piden que lo haga”. De este modo, solo la presencia de un aparente respetable narratario vuelve verosímil la narración, a costa de socavar el esfuerzo autoafirmativo del autor: "Lázaro no puede tomar la palabra por sí mismo cuando quiera y como quiera, sino sólo en el caso de que una instancia se lo requiera. El poderoso se define por poder tomar la palabra en contextos muy amplios, mientras que el subalterno se define por no poder tomar la palabra bajo su propia iniciativa” (Asensi, 2009a, 53-54).

De este modo, el requerimiento de Vuestra Merced, instando a Lázaro a hablar, insiste Asensi (2009a, 55), lo que hace es rescatar al Otro del anonimato, pero a costa de evidenciar su posición subordinada. Así, la posición de Lázaro resulta de una gran ambivalencia, pues, por un lado, acción y enunciación le otorgan un protagonismo que desafía el tradicional silencio literario en torno al individuo anónimo, pero, por otra parte, su actividad enunciativa -la cual, al fin y al cabo, no hace sino poner de manifiesto la crónica de una vida resumible en cuanto relato de una constante sucesión de amos- es fruto de un acto de imposición, de una pregunta de la que no puede escapar: ¿qué hay de cierto en el 'caso'?

No obstante, cierto es que parece que la asunción por parte de Lázaro del rol enunciativo, en calidad de relator, tiene lugar una vez que el protagonista ha logrado cierto aparente éxito dentro del engranaje social, pero toda esta imagen del self-made man no es sino una máscara que encubre todo un ejercicio de resignación e hipocresía que lleva a la aceptación por parte de Lázaro de la infidelidad de su mujer y, como consecuencia de ello, a la petición de esclarecimiento de este deshonroso episodio de manos de un enigmático narratario. Así, dirá un tanto irónicamente Martínez (2004) que "Vuestra Merced' es el 'padre' involuntario de la novela moderna, pues cometió el 'error' de darle la palabra al Otro”. No obstante, no podemos olvidar la condición de personaje literario, de arquetipo, de la figura del pícaro, lo cual supone dar otra vuelta de tuerca al tema del individuo corriente, del don nadie, que deja de serlo en el momento en el que se convierte en símbolo de un género literario: "Así pues, el enunciarse como yo, Lázaro de Tormes, y después de él, todos sus secuaces, instituye un género cuyo fundamento es la paradoja de una diferencia no diferenciable [...] El yo-pícaro, si bien es sujeto de enunciado, no opera nunca como sujeto de enunciación, lo que significa que no remite a ningún referente efectivo" (Molho, 1983, 134-135).

Si echamos un vistazo un poco más detenido a la novela, podemos ver cómo la situación de subordinación del personaje narrador, en lo concerniente al plano enunciativo, es manipulada desde dos prismas diferentes. Uno sería mixto, donde se combina el plano físico y el enunciativo, y el otro es, diríamos, puro, centrado en el ámbito puramente verbal.

Comenzando por el plano mixto, la subalternidad física y enunciativa tiene lugar ya desde las primeras páginas, cuando un Lázaro aún niño ha de enfrentarse al coercitivo interrogatorio acerca de los hurtos de Zaide: "con amenazas me preguntaban, y, como niño, respondía y descubría” (p. 20). De igual modo, las alusiones explícitas al narratario juegan también con los dos planos de la subordinación, en la medida en que evidencian el sometimiento enunciativo al receptor y la situación de inferioridad social de Lázaro: "huelgo 
de contar a Vuestra Merced estas niñerías, para mostrar cuánta virtud sea saber los hombres subir siendo bajos, y dejarse bajar siendo altos cuánto vicio" (p. 24). Por otro lado, los momentos en los cuales los distintos amos dan órdenes al pícaro no son sino un reflejo del sometimiento físico y verbal, aunque en este caso exclusivamente del personaje: "me tenía mandado" (p. 30); "los sábados cómense en estas tierras cabezas de carnero, y enviábame por una" (p. 50); "Lázaro [...] haz la cama y ve por la vasija de agua al río" (p. 82). Otras veces, la relación de subordinación enunciativa se establece, de forma retórica, no ya con un destinatario 'real', sino con una instancia religiosa, sirviendo igualmente para reflejar el sometimiento físico de Lázaro: “iOh, Señor mío - dije yo entonces-, a cuánta miseria y fortuna y desastres estamos puestos los nascidos y cuán poco turan los placeres de esta nuestra trabajosa vida!" (p. 60).

No obstante, cierto es que la subalternidad física y enunciativa es también en ocasiones subvertida, como en el episodio final con el ciego (pp. 44-45), en el que es Lázaro quien, en cierto modo, determina las acciones de su amo, al indicarle dónde debe cruzar, para evitar mojarse, con el consiguiente resultado del tremendo golpe del viejo contra un pilar, venganza esta que invertirá los roles amo-criado. Otras veces, la enunciación servirá de forma simbólica para subvertir la subordinación física, como vemos cuando Lázaro se dirige de nuevo a Dios al objeto de desear toda suerte de males al clérigo de Maqueda: "yo disimulaba, y en mi secreta oración y devociones y plegarias decía: “iSant Juan, y ciégale!'” (p. 57). Incluso la ironía, frecuente en la obra, en episodios como el del escudero -a propósito de la comida, por lo general- no hace sino reforzar la naturaleza subversiva de la enunciación -aunque Lázaro se limite a hablar consigo mismo- como mecanismo de compensación ante la subordinación física de la relación amo-criado: "-Por mi vida, que paresce éste buen pan. - ¿Y cómo, agora -dije yo-, señor, es bueno?” (p. 77); “-Vivirás más y más sano [...] Porque, como decíamos hoy, no hay tal cosa en el mundo para vivir mucho que comer poco. Si por esa vía es - dije yo entre mí-, nunca yo moriré, que siempre he guardado esa regla por fuerza” (p. 8o); “-¿Vesla ahí? Yo me obligo con ella cercenar un copo de lana. Y yo dije entre mí: 'Y yo con mis dientes, aunque no son de acero, un pan de cuatro libras”' (p. 82). Esta ironía se convertirá en cinismo, o hipocresía, cuando el arcipreste aconseje a Lázaro 'mirar hacia otro lado' en relación con la supuesta infidelidad de su mujer, haciendo así que la situación de subordinación social de Lázaro, debido al público conocimiento de su deshonra, sea subvertida mediante un acto enunciativo en el que Lázaro es de nuevo el subordinado, pero al objeto de lograr su hipotético ascenso social final: "no mires a lo que pueden decir, sino a lo que te toca: digo a tu provecho" (p. 133).

Pasando al plano de la subalternidad puramente enunciativa, Lázaro, como supuesto autor real del libro, comienza recurriendo al tópico de la humildad a la hora de describir su obra: “desta nonada, que en este grosero estilo escribo" (p. 8). En las mismas páginas iniciales, el pícaro evidenciará de forma explícita la subordinación enunciativa respecto al requerimiento del narratario, planteando así la novela como una pura deuda epistolar: "suplico a Vuestra Merced reciba el pobre servicio [...] Y pues Vuestra Merced escribe se le escriba [...] porque se tenga entera noticia de mi persona" (pp. 8 y 11). Precisamente, a la hora de dirigirse al narratario, Lázaro acentuará siempre -en consonancia también con las fórmulas retóricas- la situación de inferioridad social del narrador: "hablando con reverencia de Vuestra Merced" (p. 133).

La subalternidad enunciativa, al igual que la mixta y la física, se verá subvertida en más de una ocasión, bien fingiendo el relator un control sobre el discurso puramente falso, como 
bien sabemos desde el momento en el que conocemos la causa del relato de Lázaro - "quiero que sepa Vuestra Merced” (p. 27)-, bien negando la enunciación ajena, con el estéril propósito de no enfrentarse a su incuestionable condición de notorio cornudo: "mirá, si sois mi amigo, no me digáis cosa con que me pese [...] Desta manera no me dicen nada, y yo tengo paz en mi casa" (pp. 134-135). Esta subversión tendrá también lugar desde el plano del Lázaro personaje, cuando a requerimiento del escudero, dé cuenta de su vida, pero recurriendo a todos los embustes que considere necesarios: "preguntándome muy por extenso de dónde era [...] yo le satisfice de mi persona lo mejor que mentir supe" (p. 75).

De este modo, vemos cómo Lázaro, desde todos los planos - como personaje, narrador y supuesto autor real- marca de forma explícita sus relaciones de subordinación ante los demás agentes que intervienen en los actos comunicativos -amos, narratario y lectores, respectivamente- . Lázaro utiliza de igual modo la baza de la subversión y la ironía para resquebrajar la nítida frontera entre quien habla a requerimiento de los demás y los agentes que, según los roles adquiridos en los intercambios comunicativos de la España del XVI, pueden ejercer el control de la enunciación.

\section{CONCLUSIONES}

La picaresca irrumpió en el XVI en España rompiendo con todos los moldes que la ortodoxia novelesca había establecido hasta entonces. Por una parte, dicho género permitió dar protagonismo al individuo anónimo, al don nadie, al infame, personaje hasta entonces excluido del discurso literario $-\mathrm{y}$, hasta fechas mucho más recientes, de los textos históricos-; por otra parte, el uso de la primera persona, reservado a las memorias dignas de ser relatadas, volvía aún más insolentes las historias. ¿Qué permitía a un hombre sin honra, a un delincuente, recurrir al autobiografismo como si de un santo se tratara? Solo la necesidad de romper con los encorsetados moldes de las novelas basadas en personajes y contextos idealizados.

Desde estas coordenadas hemos de entender el Lazarillo. Sin embargo, para volver el relato verosímil, se hacía necesario moverse entre dos aguas, rompiendo con los esquemas narrativos imperantes hasta entonces pero al mismo tiempo haciendo ver la condición de subalterno, de subordinado, del protagonista, desde todos los planos, tanto físicos como enunciativos. Por ello, la novela se fragua como la consecuencia de una deuda epistolar con un respetable "Vuestra Merced", y en esta historia el protagonista, una y otra vez, mostrará su sometimiento a sus distintos amos tanto en el plano físico como el verbal.

Aun así, el autor real de la obra no deja por ello escapar la oportunidad de ofrecer mil y un ejemplos en los cuales el Lázaro personaje-narrador-autor juega a controlar acciones y discurso -mediante la ironía, el cinismo, los soliloquios...- en un enmarañado universo de verdades y mentiras en las que el lector tiene que intentar averiguar qué hay de cierto en el texto. Nada invita a pensar que el Lázaro narrador nos está contando la verdad acerca de su vida y del incómodo "caso". No obstante, al margen de la veracidad - siempre inverificable en el mundo de la ficción- de la historia, sobre la obra sobrevuela la intención de un autor que quiso dar voz a un don nadie fingiendo insertar su historia - que, al fin y al cabo, solo puede ser el relato de un sometido- en una situación comunicativa verosímil, pero dejando el suficiente margen como para que el lector avispado adivine, o vislumbre, las falsedades, fingimientos y medias verdades de una sucesión de palabras y acciones en las que, por primera vez, alguien ajeno al discurso público juega a hacerse dueño de su propia voz ante todos nosotros. 


\section{NOTAS}

1 De aquí en adelante citaremos por la mencionada edición de Cátedra, anotando tan solo la página correspondiente, para favorecer la lectura.

2 Tal y como recoge Cabo Aseguinolaza (1992, 311-349), entre la extensísima bibliografía en torno a la picaresca cabe encontrar no pocos estudios acerca de la importancia de la voz -y la estructuranarrativas en el Lazarillo. Así, desde los debates en torno a la naturaleza realista/folclórica (Rey, 1979) de una novela donde parecía primar la crítica a las novelas de caballerías (Bataillon, 1968), a partir de un texto que desvirtuaba las características de una auténtica autobiografía (Gómez Moriana, 1972), se ha ido evolucionando hacia estudios centrados en la construcción narrativa de la obra. En este sentido, es posible encontrar dos líneas de investigación fundamentales, más o menos interconectadas: a) aquella que, a partir de la oposición entre discurso y relato, busca profundizar en los diferentes niveles narrativos (Deheninn, 1980), basándose en la fractura enunciativa que se produce en el prólogo (Bell, 1973) entre las palabras del pretendido autor del texto y el comienzo del discurso del protagonista (Navarro Durán, 2003); y b) la que, fruto del valor nuclear del narratario - el enigmático "Vuestra Merced" - y de su interés por la vida de Lázaro (Hitchcock, 1971), plantea que, o bien hay un único "caso" (Lázaro Carreter, 1972) -el celebérrimo ménage à trois entre Lázaro, su mujer y el arcipreste- que da sentido y razón de ser a toda la narración (Rico, 1970), o que, por el contrario, el "caso" mencionado en el prólogo y en el últimos de los tratados son diferentes (Sobejano, 1975), y la razón de ser de la autobiografía sería la mera búsqueda de fama u honra (García de la Concha, 1981).

\section{REFERENCIAS BIBLIOGRÁFICAS}

ABAD GARCÍA, E. 2011. "Postcolonialismo, breve recorrido sobre las figuras de lo subalterno y las apariencias de enunciación”, Studia Politicae, 24, pp. 23-58.

ANGENOT, M. 2010. El discurso social. Los límites históricos de lo pensable y lo decible. Buenos Aires: Siglo XXI.

ANÓNIMO. 2006. Lazarillo de Tormes. Madrid: Cátedra.

ARIAS, L. M. 2000. "Historia (de España) e intrahistoria (del sujeto): de Unamuno a Erice", Trama \& fondo, 9, pp. 1-21.

ASENSI PÉREZ, M. 2007. “Crítica, sabotaje y subalternidad”, Lectora, 13, pp. 133-153.

ASENSI PÉREZ, M. 2009a. "De los usos del canon: el canon por venir y el Lazarillo desfigurado", Signa, 18, pp. 45-68.

ASENSI PÉREZ, M. 2009b. "La subalternidad borrosa. Un poco más de debate en torno a los subalternos”, en Spivak, G. C., ¿Pueden hablar los subalternos? Barcelona: MACBA, pp. 9-39.

BATAILLON, M. 1968. Novedad y fecundidad del Lazarillo de Tormes. Salamanca: Anaya.

BELL, A. 1973. "The rhetoric of self-defence of 'Lázaro de Tormes", Modern Language Review, 68(1), pp. 85-93.

BENDER, E. 2016. Historia del relato y relato de la historia. La obra autobiográfica de Arturo Barea. Lublin: Universidad Maria Curie-Skłodowska.

BLANCO AGUINAGA, C. 1983. "Picaresca española, picaresca inglesa: sobre las determinaciones del género", Edad de Oro, 2, pp. 49-65.

CABADO, J. M. 2011. “'Arrimarse a los buenos': necesidades vitales y artificiales en el Lazarillo", Olivar, 15, pp. 131-149.

CABO ASEGUINOLAZA, F. 1992. El concepto de género y la literatura picaresca. Santiago de Compostela: Servicio de Publicaciones de la Universidad de Santiago de Compostela. 
CELA, C. J. 1985. "Pícaros, clérigos, caballeros y otras falacias, y su reflejo literario en los siglos XVI y XVII", Edad de Oro, 4, pp. 33-46.

COLL-TELLECHEA, R. 2015. "Los límites de la representación: picaresca, censura e historia", Studia Aurea, 9, pp. 147-174.

DEHENNIN, E. 1980. "Lazarillo de Tormes en la encrucijada de enunciación y enunciado", en Actas del VI Congreso Internacional de Hispanistas. Toronto: University of Toronto, pp. 203-206.

FERNÁNDEZ TURIENZO, F. 1997. "Unamuno, lo inconsciente y la historia", Cuadernos de la Cátedra Miguel de Unamuno, 32, pp. 77-98.

GARCÍA DE LA CONCHA, V. 1981. Nueva lectura del Lazarillo. Madrid: Castalia.

GARCÍA PÉREZ, P. 1994. "El 'serse' en la historia. Historia e Intrahistoria en Unamuno", Sancho el Sabio: Revista de cultura e investigación vasca, 4, pp. 17-50.

GÓMEZ MORIANA, A. 1972. "Sobre la función del yo narrante en el Lazarillo de Tormes", Boletín de Filología Española, 42-45, pp. 54-56.

GUTIÉRREZ, J. 1989. "Unamuno entre la épica y la intrahistoria: Relectura de 'Paz en la guerra”, en Neumeister, S. (coord.), Actas del IX Congreso de la Asociación Internacional de Hispanistas. Vol. II. Berlín: Vervuert, pp. 265-274.

HITCHCOCK, R. 1971. "Lazarillo and "Vuestra Merced", Modern Language Notes, 86(2), pp. 264-266.

LÁZARO CARRETER, F. 1972. "Lazarillo de Tormes" en la picaresca. Barcelona: Ariel.

MARGENOT, M. R. 2009. "Intrahistoria en Unamuno e intratiempo en Machado", Espéculo, 42. Disponible en: https://pendientedemigracion.ucm.es/info/especulo/numero42/ intrahis.html.

MARTÍNEZ, G. 2004. "Lazarillo o la voz del otro", Espéculo, 28. Disponible en: https:// pendientedemigracion.ucm.es/info/especulo/numero28/lazarillo.html.

MEDINA, C. 2009. "Intrahistoria, cotidianidad y localidad”, Atenea, 500, pp. 123-143.

MOLHO, M. 1983. “¿Qué es picarismo?”, Edad de Oro, 2, pp. 127-136.

NAVARRO DURÁN, R. 2003. "Introducción”, en Valdés, A. de, La vida de Lazarillo de Tormes, y de sus fortunas y adversidades. Barcelona: Octaedro, pp. 9-90.

REY, A. 1979. "La novela picaresca y el narrador fidedigno", Hispanic Review, 47(1), pp. 55-75.

REY HAZAS, A. 1982. "Introducción a la novela del Siglo de Oro, I (Formas de narrativa idealista)", Edad de Oro, 1, pp. 65-105.

RIBAS RIBAS, P. 1971. "El Volkgeist de Hegel y la intrahistoria de Unamuno", Cuadernos de la Cátedra Miguel de Unamuno, 21, pp. 23-33.

RICO, F. 1970. La novela picaresca y el punto de vista. Barcelona: Seix-Barral.

RUFER, M. 2013. "Experiencia sin lugar en el lenguaje: enunciación, autoridad y la historia de los otros", Relaciones, 133, pp. 79-115.

SHARPE, J. 1996. "Historia desde abajo", en Burke, P. (ed.), Formas de hacer historia. Madrid: Alianza Editorial, pp. 38-58.

SOBEJANO, G. 1975. "Un perfil de la picaresca: el pícaro hablador", en Studia Hispanica in Honorem Rafael Lapesa. Vol. III. Madrid: Gredos, pp. 467-486.

TODOROV, T. 1987. La conquista de América. La cuestión del otro. México: Siglo XXI.

\section{NOTA SOBRE EL AUTOR}

José Antonio Calzón García es doctor en Filología Española y profesor en la Universidad de Cantabria, España. 